IRA International Journal of Management \& Social Sciences ISSN 2455-2267

Vol. 14, Issue 02 (Special Issue) pg. 64-72.

International Conference on Wellbeing: Lifespan Perspectives $\Xi^{0}$ Practices for Sustainable

Communities, 2019.

\title{
Adjustment among Adolescents of Guwahati City in Relation to Gender and Religion
}

Tahera Hoque Mozumdar ${ }^{1}$, Indranee Phookan Borooah ${ }^{2}$

${ }^{1}$ Research Scholar, Department of Psychology, Gauhati University, India \& Assistant Professor, Department of Psychology and Counselling, Assam Don Bosco University, Tapesia Garden, Sonapur-782402, Assam, India.

${ }^{2}$ Professor, Department of Psychology, Gauhati University, India.

DOI: $10.21013 /$ jmss.v14.n2sp.p8

(c) Authors.

Type of Review: Peer Reviewed under the Responsibility of the conference's Scientific Committee.

Disclaimer: The copyright to this work is retained by the authorship. This work contains the opinions E? views of the authorship solely and the same are not the views or opinions of the IRA. IRA disclaims of any

harm or loss caused due to the published content to any party. 


\begin{abstract}
Adjustment of adolescents in relation to their gender and religion was investigated. Gender (Male and Female) and religion (Hindu and Muslim) were treated as independent variables whereas adjustment was treated as a dependent variable. The sample comprised of 282 high school students (from class IX and X) of state Government schools of Guwahati city that belonged to lower middle-income group. The multi-stage sampling method was used for selecting the sample. Upadhyay-Saxena Socio-Economic Status (USSES) Scale, Adjustment Inventory for School Students (AISS) and Personal Information Data sheet were administered to all the participants. Mean, Standard Deviation and ANOVA were calculated to analyze the responses. The findings of the study revealed that females are better adjusted in the areas of emotional adjustment, educational adjustment and also in terms of total adjustment in comparison to males, which implies gender has a significant effect in the area of emotional adjustment, educational adjustment and also in the total adjustment of the adolescents. But no significant difference was found in the area of social adjustment between male and female adolescents. Further, it was found that religion has no significant effect on the adjustment among adolescents, which means that there is no significant difference in the adjustment of Hindu and Muslim adolescents of Guwahati city.
\end{abstract}

Keywords: Adolescents, Adjustment, Gender, Religion.

\title{
Introduction:
}

Adolescence is the transitional period from childhood to adulthood. It is an important period because during this period the adolescent will lay foundations on which to build adult attitudes and behaviour patterns. Due to some important biological, psychological and social changes adolescents have to adjust with their own changes in personality on one side and the changing socio-economic environment on the other side (Borooah \& Mozumdar, 2015). During this period usually, adolescents start to see life through rose-tinted glasses and they keep unrealistic expectations about life. But whenever they confront the harsh reality of life they cannot accept it and then starts the struggles. It causes unhappiness, loneliness, revolts against elders as well as society, negative thinking and negative behaviour among adolescents. These unusual situations arise due to lack of adjustment among adolescents.

Adjustment is the process by which a living organism maintains a balance between its needs and the circumstances that influence the satisfaction of these needs (Shaffer, 1961 as stated in Mangal K.S., 2011). According to Arkoff (1968), "Adjustment is the interaction between a person and his environment. How one adjusts in a particular situation depends upon one's personal characteristics as also the circumstances of the situation. In other words, both personal and environmental factors work side by side in adjustment. An individual is adjusted if he is adjusted to himself and to his environment".

Adjustment is a continuous process from birth until death. An individual's needs, as well as his environmental conditions, keep on changing from time to time. He/she has to adjust with those changing environmental demands as well as with his personal needs. According to Arkoff (1968), there is nothing like satisfactory or complete adjustment which can be achieved once and for all times. It is something that is constantly achieved and re-achieved by us.

Adjustment or changing of oneself or one's surroundings according to the demand of the external environment can be considered as one of the basic needs for survival in this world. It is essential in today's time of globalization. Because of the impact of globalization competition has increased in all spheres of life such as in education, work organizations, economics, socio-cultural resources, life styles etc. The increased global interaction and competition has led to one's life becoming full of stress and for survival, one has to adjust with these constantly changing environmental demands. The person who can adapt in today's competitive world effectively can live life happily and successfully, otherwise, the person will vanish, be maladjusted and live a miserable life or he/she will become the disturbing factor not only for his family but also for the society.

\section{The significance of the present study:}

Adolescence is an important period of life span because of both immediate as well as long-term effects on individuals' attitudes and behaviour. Based on the importance of this period of life span the present research selected adolescents as its sample.

International Conference on Wellbeing: Lifespan Perspectives E Practices for Sustainable Communities, 2019. 
Biological sex of an individual (P. A. Mary \& K. Manikandan, 2015) and the gender roles (the characteristics and behaviours) that a society or culture attribute to the sexes may have a significant effect on their psychological characteristics. It was also reported that boys mature, on the average, later than girls; they have a shorter period of early adolescence, although they are regarded as adults when they reach eighteen, just as girls are. As a result, they frequently seem more immature for their age than a girl (Hurlock, 1981). The research found that boys are significantly better adjusted than girls on the emotional adjustment area (Raju and Rahamtullah 2007 as stated in Agarwal, 2014). Roy, Ekka and Ara (2011) (as stated in Agarwal, 2014) observed that female students were better adjusted than male students. However, Mahmondi (2010) (as stated in Agarwal, 2014) found that gender had no differential influence over adjustment scores in the home, health, emotional and social area.

Guwahati city is the Headquarter of Kamrup district and it is also regarded as the "Gateway of North-East India". Therefore, in the present study, Guwahati city was selected for the collection of the sample. According to the 2001 census, in Kamrup District $72.80 \%$ of the population belongs to the Hindu religion, whereas $24.78 \%$ belongs to the Muslim religion. Hindu is the majority dominant group and Muslim is included in a minority group in Kamrup District. Hatter and Ottens (1998) (as stated in 23rd March 2015, UKESSAYS) reported that empirical evidence suggests that being a member of a minority group may be experienced as a stressful life event and may act as an antecedent to various emotional problems. Research shows that there is a significant difference in emotional and social adjustment among Hindu and Muslim people (Patel, 2014). Another study found that Hindu female undergraduates (aged 15 to 20 years) were significantly better adjusted than Muslims female undergraduates (J. Qamar, 1990). However, Singh (1984) in his study found no significant differences in any area of adjustment (home, social and emotional, health, or school adjustment) among Hindu and Muslim participants.

To the researcher's knowledge till yet no psychological research studies have been conducted in any of the State Government schools of Guwahati city; instead, most of the research studies were limited to private schools in Guwahati city. It is observed that one of the biggest tragedies of the Assam State is the deplorable condition of the Government schools at present and its free fall even now. Therefore, many inherent talents and limitless potentials have been deprived of quality education today (Bhuyan, K. P. 2016). In one of the studies which were conducted in Secondary schools of Kaliabor sub-division, Nagaon district by Barthakur \& Kalita (2015), they revealed that $62 \%$ of Government schools have basic facilities for healthy environment of schools whereas $80 \%$ of the private schools provided such basic facilities to their schools. A healthy school environment not only helps the student to increase academic achievement but also helps to develop the social ability, adjustment, moral value, self-confidence etc. Based on the above-mentioned observations the present research limited its boundary only to State level Government schools instead of private schools.

Based on the above-mentioned discussions and review of previous research studies the present research aims to assess the adjustment level of male and female adolescents of different religions.

\section{Objectives:}

1. To assess the level of emotional, social, and educational adjustment among Male and Female Adolescents.

2. To compare the level of emotional social, and educational adjustment between Male and Female Adolescents.

3. To assess the level of emotional, social, and educational adjustment among Hindu and Muslim adolescents.

4. To compare the level of emotional, social, and educational adjustment between Hindu and Muslim adolescents.

\section{Hypotheses:}

1. There will be no significant difference in emotional adjustment between Male and Female Adolescents.

2. There will be no significant difference in social adjustment between Male and Female Adolescents.

3. There will be no significant difference in educational adjustment between Male and Female Adolescents.

4. There will be no significant difference in emotional adjustment between Hindu and Muslim adolescents.

5. There will be no significant difference in social adjustment between Hindu and Muslim adolescents.

6. There is will be no significant difference in educational adjustment between Hindu and Muslim adolescents. 


\section{Method}

\section{Participants:}

The participants of the study comprised of 282 adolescents of class XI and X in the age range of 14 to 16 years. Samples were taken from various State Government schools of Guwahati city, Assam. Among the total number of adolescents, 129 were male and 153 were female. Regarding the religious affiliation, 135 were Hindu and 147 of them were Muslims.

\section{Sampling Method:}

282 adolescents were selected by Multi-Stage Sampling method. The stages followed for selection of sample are mentioned below-

First Stage - From the six zones of Guwahati city, four zones were selected by convenience sampling.

Second Stage - From each zone, one State Government school was selected randomly. Total four schools were selected randomly.

Third Stage - Then as per the convenience of the school authority, and after taking prior permission from the same, the researcher visited the schools and included all the students in a class in the administration of the tools, so that sample size of participants was left open.

\section{Variables:}

\section{Independent Variables:}

Gender (Male and Female)

Religion (Hindu and Muslim)

Dependent Variable: Adjustment

\section{Measures:}

(1) Upadhyay-Saxena Socio-Economic Status Scale (SESS): This scale was developed by Sunil Kumar Upadhyay and Alka Saxena, Kanpur. The scale consists of 31 items in five parts related to (i) Personal Information (ii) Family (iii) Education (iv) Income and (v) Others (Cultural \& material possessions). The test-retest reliability was reported to be 0.83 and the validity of the scale was reported as 0.78 . Administration of SESS is very simple. There is no time limit, but generally, students take 20-25 minutes to complete it. Responses are scored according to the scoring key provided in the manual.

(2) Adjustment Inventory for School Students (AISS): This scale was developed by A. K. P. Sinha and R. P. Singh. There are three areas of adjustment in this scale, which are: Emotion, Social and Educational adjustment. This scale has 60 items with 20 items in each of the three areas of adjustment: emotional, social and educational. Responses are taken in 'yes' and 'no' for each item. The split-half reliability is 0.95 with product moment correlation between inventory scores and criterions ratings being 0.51 . For each response indicative of adjustment ' 0 ' is given otherwise ' 1 ' is given. While high scores on AISS indicate poor levels of adjustment, low scores indicate good adjustment. The minimum score on the AISS is 0 while the maximum score is 60 .

(3) Personal Information Data sheet: It was prepared by the researcher herself. The personal Information Data Sheet was used to find out the following information -

- Socio-demographic information of the participants.

- Additional Information regarding other family members.

- Information regarding the social network.

- Information about the usage of social sites. 
- Information about relationship with opposite sex.

Statistical Analysis:

- Personal hobbies.

In the present investigation, F-test (two way ANOVA) and descriptive statistics such as Mean and Standard Deviation were utilized in studying the Adjustment of adolescents in relation to Gender and Religion.

\section{Procedure:}

First, the questionnaires were translated from English to Assamese by both the researcher and her research guide collaboratively. Again it was translated back into English to ensure that the meaning is not lost in the Assamese version. The translation was then rechecked by experts from the Psychology field. These processes were followed to ensure the face validity of the tools.

The whole Guwahati area is broadly divided into six zones; these are East Zone, West Zone, South Zone, Dispur Zone, Central Zone and Lokhra Zone and these zones consist of 60 wards. Each of these wards consists of some areas. Therefore, to find out the different State Government schools which are scattered in different areas of Guwahati city the researcher first collected the Zonal map of Guwahati city from the office of Guwahati Municipal Corporation, Lokhra, Assam, along with the list of different areas which lie in each ward. After collecting the Zonal map the researcher selected four zones from total six zones and these selected four zones are- Dispur Zone, East Zone, West Zone and South Zone.

Then the researcher collected the list of different State Government schools in each Zone of Guwahati city along with their location area from the office of the Inspector of Schools, Pan Bazar, Guwahati. Then four State Government schools were selected randomly from each of those four selected zones. After selecting the schools, the researcher went to all the four schools to take prior permission for data collection from the school Head Masters/ Head Mistresses. Prior consents were also ensured from all the participants before collecting data. In each school, all the sections of both the classes IX and X were taken and all students were included in the administration, keeping the sample size free. Before administration of the tools first rapport was built with the participants, then all the set of questionnaires were distributed to all the participants and necessary instructions were provided. The students were informed that this data collection would be used only for research purpose and was requested to give their honest reply. They were also given assurance of maintaining confidentiality. Five minutes rest was provided in the midst of administration of two questionnaires and after completing the tools some refreshments like chocolates were distributed for participating in this investigation. After completing the data collection the participants, school Head Masters, teaching, and non- teaching staffs were thanked for their cooperation for smooth conduction of the research activities.

After collecting the data from all the four schools scoring were done manually, where 97 numbers of questionnaires were found incomplete and therefore those were rejected. After completing the scoring, among total 373 respondents, 282 respondents were selected who belong to Lower Middle Income Group as it covers the major number of participants in comparison to other socioeconomic status groups and therefore this income group was kept constant by excluding the other socio-economic groups. Then data of those 282 respondents were entered, calculated and interpreted with the help of SPSS software.

\section{Results:}

Table 1: Shows the Mean and SD of Male and Female adolescents in terms of Emotional Adjustment, Social Adjustment, Educational Adjustment and Total Adjustment. The Mean \& SD for Emotional Adjustment 6.28(3.577) \& 4.86(2.782), for Social Adjustment 6.24(2.885) \& 6.11 (2.440), for Educational Adjustment $6.29(3.105) \& 5.23(2.921)$ and for total Adjustment 18.75(7.605) \& 16.16(6.269).

In the area of Emotional Adjustment, the level of adjustment for male and female were average and good respectively. In the area of Social, Educational and Total adjustment the level of adjustment for both the male and female was found to be average. 
Table 1: Showing Mean, SD and F-test (ANOVA) of Male and Female adolescents in terms of their Emotional, Social, Educational and Total Adjustment

\begin{tabular}{|c|c|c|c|c|c|c|}
\hline $\begin{array}{l}\text { Dependent } \\
\text { variable }\end{array}$ & Gender & Mean & $\begin{array}{l}\text { Standard } \\
\text { Deviation }\end{array}$ & $\mathrm{F}$ & P Value & $\begin{array}{l}\text { Level of } \\
\text { Adjustment }\end{array}$ \\
\hline \multirow{2}{*}{$\begin{array}{l}\text { Emotional } \\
\text { Adjustment }\end{array}$} & Male & 6.28 & 3.577 & \multirow[t]{2}{*}{$13.593 * *$} & \multirow[t]{2}{*}{.000} & Average \\
\hline & Female & 4.86 & 2.782 & & & Good \\
\hline \multirow{2}{*}{$\begin{array}{l}\text { Social } \\
\text { Adjustment }\end{array}$} & Male & 6.24 & 2.885 & \multirow[t]{2}{*}{$.231^{\mathrm{NS}}$} & \multirow[t]{2}{*}{.631} & Average \\
\hline & Female & 6.11 & 2.440 & & & Average \\
\hline \multirow{2}{*}{$\begin{array}{l}\text { Educational } \\
\text { Adjustment }\end{array}$} & Male & 6.29 & 3.105 & \multirow[t]{2}{*}{$7.747 * *$} & \multirow[t]{2}{*}{.006} & Average \\
\hline & Female & 5.23 & 2.921 & & & Average \\
\hline \multirow{2}{*}{$\begin{array}{l}\text { Total } \\
\text { Adjustment }\end{array}$} & Male & 18.75 & 7.605 & \multirow[t]{2}{*}{$9.377 * *$} & \multirow[t]{2}{*}{.002} & Average \\
\hline & Female & 16.16 & 6.269 & & & Average \\
\hline
\end{tabular}

$$
* *=\mathrm{p}<.01, \mathrm{NS}=\text { not significant }
$$

Table 1 also shows the individual effect of gender (i.e. the $\mathrm{F}$ value for Gender) on all the areas of Adjustment separately. The F value for Emotional Adjustment was found to be 13.593, which is statistically significant at the 0.01 level. The $\mathrm{F}$ value for Social Adjustment was found to be .231, which is not significant. The $\mathrm{F}$ value for Educational Adjustment was found to be 7.747, which is statistically significant. The F value for Total Adjustment was found to be 9.377, which is statistically significant.

Table 2: Shows the mean and SD of Hindu and Muslim adolescents in terms of Emotional Adjustment, Social Adjustment, Educational Adjustment and Total Adjustment. The mean \& SD for Emotional Adjustment 5.67(3.343) \& 5.36(3.151), for Social Adjustment 6.01(2.759) \& 6.31(2.545), for Educational Adjustment $6.06(3.185) \& 5.39(2.890)$ and for total Adjustment 17.70(7.469) \& 17.02(6.587). The level of adjustment in all the areas is average.

Table 2: Showing Mean and SD of Hindu and Muslim adolescents in terms of their Emotional, Social, Educational and Total Adjustment

\begin{tabular}{|c|c|c|c|c|c|c|}
\hline $\begin{array}{l}\text { Dependent } \\
\text { variable }\end{array}$ & Religion & Mean & $\begin{array}{l}\text { Standard } \\
\text { Deviation }\end{array}$ & $\bar{F}$ & P Value & $\begin{array}{l}\text { Level of } \\
\text { Adjustment }\end{array}$ \\
\hline \multirow{2}{*}{$\begin{array}{l}\text { Emotional } \\
\text { Adjustment }\end{array}$} & Hindu & 5.67 & 3.343 & \multirow[t]{2}{*}{$.339^{\mathrm{NS}}$} & \multirow[t]{2}{*}{.561} & Average \\
\hline & Muslim & 5.36 & 3.151 & & & Average \\
\hline \multirow{2}{*}{$\begin{array}{l}\text { Social } \\
\text { Adjustment }\end{array}$} & Hindu & 6.01 & 2.759 & \multirow[t]{2}{*}{$.931^{\mathrm{NS}}$} & \multirow[t]{2}{*}{.336} & Average \\
\hline & Muslim & 6.31 & 2.545 & & & Average \\
\hline \multirow{2}{*}{$\begin{array}{l}\text { Educational } \\
\text { Adjustment }\end{array}$} & Hindu & 6.06 & 3.185 & \multirow[t]{2}{*}{$2.346^{\mathrm{NS}}$} & \multirow[t]{2}{*}{.127} & Average \\
\hline & Muslim & 5.39 & 2.890 & & & Average \\
\hline \multirow{2}{*}{$\begin{array}{l}\text { Total } \\
\text { Adjustment }\end{array}$} & Hindu & 17.70 & 7.469 & \multirow[t]{2}{*}{$.329^{\mathrm{NS}}$} & \multirow[t]{2}{*}{.567} & Average \\
\hline & Muslim & 17.02 & 6.587 & & & Average \\
\hline
\end{tabular}

NS= not significant

Table 2 also shows the individual effect of religion (i.e. the $\mathrm{F}$ value for Religion) on all the areas of Adjustment separately. The F value for Emotional Adjustment was found to be.339, which is not statistically significant. The F value for Social Adjustment was found to be.931, which is not significant. The F value for Educational Adjustment was found to be 2.346, which is not statistically significant. The F value for Total Adjustment was found to be .329 , which is not statistically significant. 


\section{Discussion:}

The present study aimed to investigate the effect of Gender and Religion on adjustment among adolescents of State Government schools in Guwahati city.

In the present study gender significantly affected the emotional adjustments of adolescents (Table 1) as females have better emotional adjustment than males. This finding supports previous research (Bhagat Pooja, 2016).

No significant differences were found between male and female adolescents in terms of Social Adjustment and adolescents of both genders have an average level of social adjustment. This finding supports previous researches (M. Armin, 2011; Borooah \& Mozumdar, 2015).

Further, although the Educational Adjustment level was found to be average for both the male and female adolescents, statistically significant difference was found among the male and female adolescents in case of their Educational Adjustment. Therefore, it may be said that gender significantly affected the Educational Adjustment of adolescents of Guwahati city, but both the groups had acceptable levels of adjustment in this area although adjustment of females was found to be better than males. It's indicating that females take more interest in all the school (curricular and co-curricular) activities than their male counterparts. This finding supports previous research (B. Sarah, 2012).

It was observed in the above-mentioned results that females were better adjusted in almost all the areas of adjustment (Emotional, Educational and Total Adjustment) except in Social adjustment than males. That means there is a significant difference among the male and female adolescents in case of their Emotional, Educational and Total Adjustment (Table 1).

Biological factors may have an influence upon the gender differences which were found in the area of Emotional, Educational and Overall adjustment. According to Hurlock (1981) boys mature, on the average, later than girls, although they are regarded as adults when they reach eighteen, just as girls are. As a result, they frequently seem more immature for their age than a girl. Therefore, due to this early maturation, adolescent girls may be able to think more critically about the world around them and also be able to take decisions more sophisticatedly than the adolescent boys and this, in turn, may be affecting their emotional, educational and also their overall adjustment level.

No significant differences were found between Hindu and Muslim adolescents in terms of their Emotional, Social, Educational and Total Adjustment, which implies religion of participants did not have an effect on their Emotional, Social, Educational and Total Adjustment. These present findings are consistent with the previous study (Singh 1984). However, the present findings contradict a previous study conducted by Patel, B.S. (2014), where he found a significant difference between Hindu and Muslim people in relation to their Emotional and Social Adjustment.

Very few researches have focused on the effect of religion (Hindu and Muslim) on the adjustment of adolescents, especially in Assam, as far as the knowledge of investigator goes.

It was observed that the minority group of people usually face various problems anywhere especially the problem of prejudice and discrimination. In fact, in many places of India, the religious minority groups of people are still facing the problems of prejudice, stigmatization and discriminations. Therefore, being a member of the minority group may result in negative self-evaluations and self-perceptions (Jensen, White \& Galliher, 1982 as stated in UKESSAYS, 2015). According to Alvarez \& Helms (as stated in UKESSAYS, 2015) negative self-perceptions, in turn, are likely to be associated with poor psychological adjustment outcomes. However, the present research shows that in Assam, it appears that self-evaluations and self-perceptions of the Muslim students are perhaps not affected by their minority status.

Ganesan (2013) in his article also mentioned that the rivalry in Assam was not between Hindus and Muslims. This very picture of Assam is clearly revealed in the present study as no significant difference was found among Hindu and Muslim adolescents in case of their Emotional, Social, Educational and Total Adjustment. It was found that in all the areas of Adjustment (Emotional, Social, Educational and in overall adjustment), the level of 
adjustment is average in case of both Hindu and Muslim adolescents. It means in Guwahati city the Muslim adolescents do not suffer from maladjustment. It indicates that though the Muslim is the religious minority group in Guwahati city, they do not feel that they are discriminated, stigmatized and prejudiced by another dominant religious group. In fact, they are also living along with the Hindus by enjoying on par similar rights and opportunities and there is unity among both the religious groups.

However, it must be noted that the level of adjustment in the case of both Hindu and Muslim adolescents are not able to reach the category of excellent and good adjustment level. This could probably be because they belong to lower middle-income group and it was found that most of their parent's occupations are daily wage labour, hotel waitress, cook in schools, peon, security guard, farmer etc. and also in case of maximum adolescents, their parental educational level is till school level. It was also found that for most of the adolescents both the parents are working. Therefore, it can be said that maybe the lack of poor parenting practices and lower socio economic status are influencing the adjustment level of both Hindu and Muslim adolescents. May be because of these factors they are not able to reach an excellent or good level of adjustment.

\section{Limitations:}

The limitations of the present study are mentioned below----

$>$ One of the limitations of the study is time constraints during data collection in the schools.

$>$ Some of the students were not cooperative as they submitted the half-filled questionnaires and in the present study 97 numbers of questionnaires were found incomplete and had to be rejected.

$>$ It was noted that most of the students of the State Government schools were below average students. Though the questionnaires were translated into the Assamese language, but most of them were unable to understand the questionnaire items. It was required to explain repeatedly to them. Therefore, their understanding level may influence the result of the present study.

$>$ In some schools due to the presence of teachers during data collection, the student's responses may have been affected.

\section{Suggestions and Recommendations for further research:}

$>$ It was observed that nowadays in the State Government Schools of Assam the infrastructure facilities have improved and also highly qualified teachers are being appointed but most of the students are below average till now. Therefore, more research should be done extensively in those schools, especially in primary schools, to find out the causes of under-achievement.

$>$ In future, a comparative study on the influence of parenting styles on adolescents' adjustment in State Government schools can be carried out.

$>$ A comparative study on Lower Income Group, Lower Middle Income Group, Middle-Income group, Higher Middle-Income group, Family environment and adjustment among adolescents can be carried out in the State Government schools of various districts of Assam.

\section{References:}

[1]. Agarwal, A. (2014). Adjustment, emotional control and perceived loneliness among adolescents. The International Journal of Indian Psychology, Volume: 01 | Issue: 04 | ISSN 2348-5396.

[2]. B. Sarah, (2012). Adjustment of Secondary School Students. Scholarly Research Journal for Interdisciplinary Studies, Vol. - I, Issue-III, P. 430.

[3]. Barthakur \& Kalita (2015). School Environment and Its Impact on Academic Achievement of Secondary Students. School Psychology: Enhancing Psychological Competencies. Puducherry Co-op. Book Society Ltd., P. 163, Puducherry-605008, India.

[4]. Bhagat Pooja (2016). Comparative Study of Emotional Adjustment of Secondary School Students In Relation to Their Gender, Academic Achievement and Parent-Child Relationship. International Journal of Recent Scientific Research, Vol. 7, Issue, 7, pp. 12459-12463.

[5]. Bhuyan, K. P. (2016). Challenges of School Education in Assam. Assam Tribune, 20th June.

[6]. Borooah, P. I. \& Mozumdar, H. T. (2015). Perceived Loneliness and Social Adjustment among Adolescents. School Psychology: Enhancing Psychological Competencies. Puducherry Co-op. Book Society Ltd., P. 653, Puducherry605008, India. 
[7]. Ganesan, B.V. Three decades after Assam movement: a study on identity. The Hindu, December 03, 2013.

[8]. How Minority Influences the Mental Health of Adolescents (23rd March, 2015). UKESSAYS, Copyright (C) $2003-$ 2017, Venture House, Cross Street, Arnold, Nottingham, Nottinghamshire, NG5 7PJ.

[9]. Hurlock, B. E. (Fifth Ed.). Developmental Psychology: A Life-Span Approach. Tata McGrawHill Publishing Company Limited, New Delhi.

[10]. Jahan, Qamar. 1990. Study of Communal Prejudice as Related to Adjustment. Manas, vol. 37, pp. 31-39.

[11]. M. Armin (2011). Influences gender on adjustment and self-esteem among adolescents Journal of American Science, 7(7):51-54]. (ISSN: 1545-1003). http://www.americanscience.org.

[12]. Mangal, K.S. (2011). Advanced Educational Psychology ( $2^{\text {nd }}$ edition). PHI Learning Private Limited, New Delhi.

[13]. P. A. Mary \& K. Manikandan (2015). Role of Self-Efficacy and Family Environment in Regulating Psychological Well Being of Adolescents. International Research Journal of SocialSciences, Vol.4(12),8-14.ISSN2319-3565.

[14]. Patel, B.S. Social Adjustment of Hindu and Muslim People. International Journal of Research in all Subjects in Multi Languages, Vol. 2, Issue: 3, March 2014, (IJRSML) ISSN: 2321 - 2853.

[15]. Singh, Rajendra (1984). Adjustment Patterns of Adolescents as a Function of Religious Orientations. Child Psychiatry Qarterly, Vol. 17, pp. 104-108.

[16]. Sinha, A.K.P. \& Singh, R.P (1993). Manual for Adjustment Inventory for School Students (AISS). National Psychological Corporation, Agra.

[17]. Statistical Handbook Assam 2010. Directorate of Economics and Statistics, Government of Assam, Guwahati-28.

[18]. U. K. Sunil and S. Alka. Manual for Upadhyay-Saxena Socio-Economic Status Scale. H.P. Bhargava Book House, 4/230, Kachari Ghat, Agra-282004. 